\title{
BMJ Open Quality Operations management on the front line of COVID-19 vaccination: building capability at scale via technology- enhanced learning
}

\author{
Iain M Smith (D) , ${ }^{1}$ Elaine Bayliss, ${ }^{2}$ Hollie Salisbury, ${ }^{3}$ Ali Wheeler ${ }^{3}$
}

To cite: Smith IM, Bayliss E, Salisbury H, et al. Operations management on the front line of COVID-19 vaccination: building capability at scale via technology-enhanced learning. BMJ Open Quality 2021;10:e001372. doi:10.1136/ bmjoq-2021-001372

Received 26 January 2021 Accepted 25 June 2021

\section{Check for updates}

(c) Author(s) (or their employer(s)) 2021. Re-use permitted under CC BY-NC. No commercial re-use. See rights and permissions. Published by BMJ.

${ }^{1}$ Improvement Capability Building \& Delivery Group, NHS England, Newcastle Upon Tyne, UK

${ }^{2}$ Improvement Capability Building \& Delivery Group, NHS England, Coventry, UK

${ }^{3}$ Countess of Chester Hospital NHS Foundation Trust, Chester, UK

Correspondence to Dr lain M Smith; iain.smith@nhs.net

\section{ABSTRACT}

The globe is gripped by the COVID-19 pandemic. Mass population vaccination is seen as the solution. As vaccines become available, governments aim to deploy them as rapidly as possible. It is important, therefore, that the efficiency of vaccination processes is optimal. Operations management is concerned with improving processes and comprises systematic approaches such as Lean. Lean focuses explicitly on process efficiency through the elimination of non-value adding steps to optimise processes for those who use and depend on them. Technology-enhanced learning can be a strategy to build improvement capability at scale. A massive online programme to build capability in Lean has been developed by the regulator of England's National Health Service. Beta testing of this programme has been used by some test sites to refine their COVID-19 vaccination processes. The paper presents a case example of massive online learning supporting the use of Lean in the day-to-day operations management of COVID-19 vaccine processes.

The case example illustrates the challenges that vaccination processes may present and the need for responsive and effective operations management. Building capability to respond rapidly and systematically in dynamic situations to optimise flow, safety and patient experience may be beneficial.

Given the national imperative to achieve mass vaccination as rapidly as possible, systematic improvement methods such as Lean may have a contribution to make. Massive online programmes, such as that described here, may help with this effort by achieving timely knowledge transfer at large scale.

\section{PROBLEM}

The globe is gripped by the COVID-19 pandemic. ${ }^{1}$ Mass population vaccination is considered the solution. ${ }^{1}$ As vaccines become available, governments aim to deploy them as rapidly as possible. In the UK, the Joint Committee on Vaccination and Immunisation (JCVI) has provided advice on vaccine prioritisation and a delivery plan developed to fully vaccinate the most vulnerable groups with two doses and offer all adults a first dose by end of July. ${ }^{23}$ It is important, therefore, that the efficiency of vaccination processes is optimal.

Operational managers of vaccination processes must contend with many complexities and uncertainties. These include, for example: multiple vaccines requiring double dose regimens ${ }^{2}$; multiple, phased cohorts to invite for vaccination predominantly prioritised on age and vulnerability ${ }^{3}$; site management (ingress and egress); socially distanced queuing $^{2}$; and overall process flow. Furthermore, the needs of the various phased cohorts may not be homogenous and therefore difficult to meet. Designing and optimising processes to achieve this will likely be an ongoing effort. Operational managers will require responsive, rapid cycle improvement and change skills to meet this challenge.

Operations management is concerned with the design, administration and improvement of processes. ${ }^{4}$ Operations management comprises systematic approaches to improvement such as Lean, which focuses explicitly on process efficiency. ${ }^{4}$ Through the elimination of non-value adding process steps, Lean aims to optimise processes for those who use and depend on them. ${ }^{5}$ Building capability rapidly and at scale may be helpful to support the national vaccination effort.

\section{BACKGROUND}

The quadruple aim of improving care quality, population health, per-capita cost and staff experience of care provision is widely promoted across healthcare systems internationally. ${ }^{6}$ Like most healthcare systems, the National Health Service (NHS) faces challenges associated with population demographics and rising care costs, ${ }^{7}$ and the objectives of the quadruple aim are embedded within its long-term plan for sustainable health and care. ${ }^{8}$ Systematic improvement methods have been promoted as a means of supporting the transformation and change 
required. ${ }^{9}$ Many of these methods are drawn from the field of operations management, which is concerned with the design, administration and improvement of production and service processes. ${ }^{4}$ Operations management methods that have been applied in healthcare include: six sigma, theory of constraints, business process engineering, statistical process control and Lean. ${ }^{10}$ Lean in particular has become popular. In the English NHS, the national regulator of provider trusts, NHS England and Improvement (NHSE\&I), has invested in a programme to embed Lean in several English NHS trusts. Initially, five trusts were supported by the Virginia Mason Institute (VMI). VMI is the consulting arm of Virginia Mason Medical Centre, a USA-based healthcare system with an international reputation for their adoption of Lean to improve quality and safety. ${ }^{511-14}$ A further seven trusts have received support from an internal NHSE\&I consulting team. ${ }^{5}$

To maximise the impact and return on investment, there is a need to share the programme's knowledge outputs widely across the NHS. NHSE\&I's partnership programme with VMI is subject to an evaluation by Warwick Business School (WBS) which is capturing knowledge outputs ${ }^{14}$ and one at-scale strategy to share learning widely is technology-enhanced learning (TEL).

TEL is an approach that applies information technologies to the learning process. ${ }^{15}$ Increasingly, TEL methods are considered beneficial to transforming healthcare education and training as they can overcome geographical and time barriers to provide effective learning. ${ }^{16} 17$ TEL can also be a strategy for large-scale improvement capability building. ${ }^{18}$ Massive open online courses (MOOCs) are a TEL method considered a significant technological and pedagogical advancement. ${ }^{19}$ MOOCs are designed to accept unlimited numbers of participants and can attract large, national and international audiences and can be used to share knowledge and deliver learning at scale. ${ }^{19} 20$
MOOCs have been identified as playing a major role in medical education, ${ }^{2021}$ and online courses have been identified as efficient and effective viable alternatives to traditional quality improvement (QI) training. ${ }^{21}$ NHSE\&I's Improvement Capability Building and Delivery (ICBD) team has experience of developing MOOCs, including one of the first to provide health and care staff with free, large-scale access to foundational QI knowledge (such as the model for improvement)..$^{22}$

To share knowledge outputs from the VMI programme, NHSE\&I's ICBD team has developed a TEL programme that will comprise several MOOCs. The programme has been developed with input from an advisory board that comprised the WBS evaluation team and chief executive representatives from VMI partnership trusts and trusts receiving NHSE\&I consulting support. The first MOOC, Lean Fundamentals, introduces foundational Lean improvement concepts and tools through a practical, structured learning-in-action approach that can be applied by participants immediately to their improvement projects. A free course, it comprises an induction module followed by six 1-hour content modules available 24/7 over an 8-week period to support health and care staff, particularly operational managers, to implement process improvements. To the best knowledge of the authors, the Lean Fundamentals MOOC described in this paper is the first to offer Lean knowledge and skills specifically tailored for health and care. Table 1 below presents an overview of the MOOC's modules.

Initially alpha-tested with ICBD staff in November 2020, the course was beta tested with frontline NHS services throughout December 2020 and early January 2021. Forty participants were recruited as beta testers from a broad geography across the English NHS representing a variety of organisational settings including acute hospitals, community provision and integrated care systems. Beta testers' experience of Lean varied from none to highly

\section{Table 1 Overview of the lean fundamentals MOOC modules}

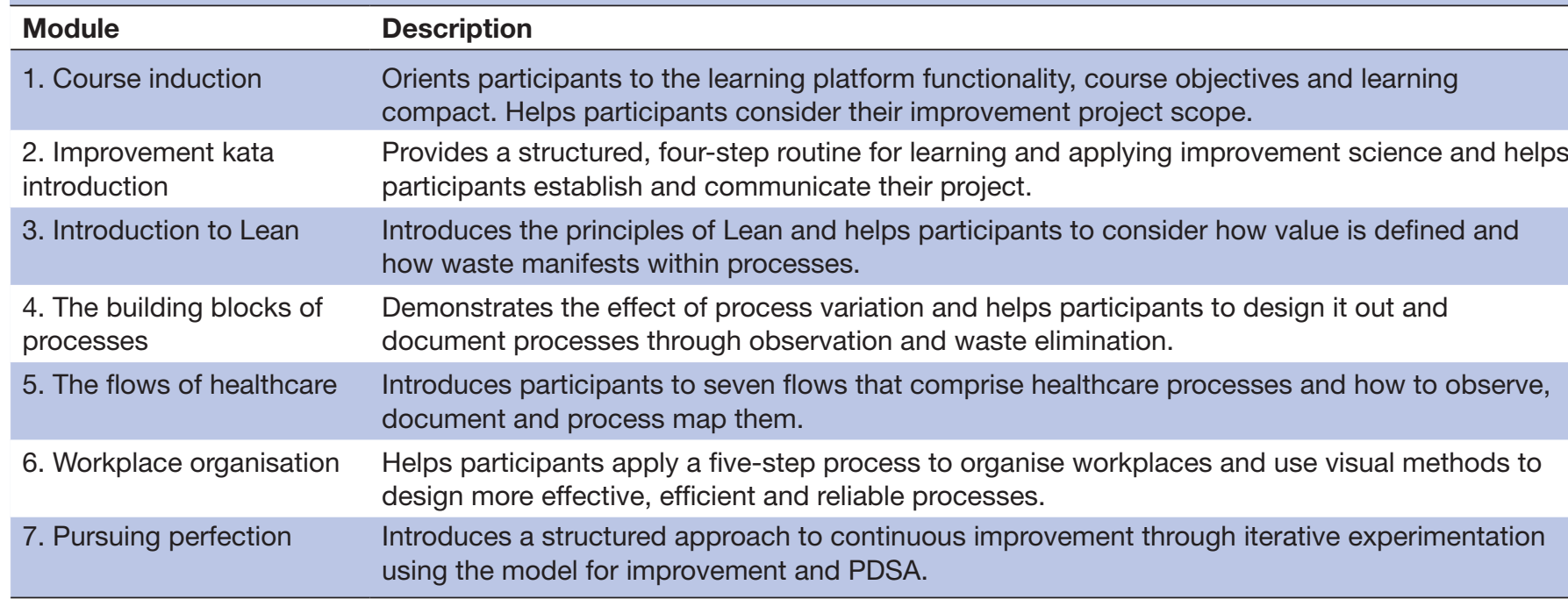

MOOC, massive open online course; PDSA, plan-do-study-act. 
experienced. With the approval of the first COVID-19 vaccine in the UK on 2 December $2020,{ }^{23}$ some beta testers chose to apply the programme to improve the process established for initial roll out to the first of the JCVI's priority groups.

Due to the severity of the current situation and need to deploy vaccines rapidly at scale, this rapid QI report has been produced to capture and share learning on the potential for TEL, massive online and Lean to support operations management at the frontline of the COVID-19 vaccination effort. A case example from the Lean Fundamentals beta test is shared below to illustrate its application to COVID-19 vaccination processes.

The case took place at an acute trust in northern England serving a population of approximately 425,000 people. The trust had initially set up a process to start vaccinating its frontline staff but was subsequently requested to help with the effort to vaccinate care home staff and those aged over 80 years. A second site was established within the same building dedicated to the vaccination of people aged over 80 years (with care home staff joining the trust's existing staff process). As the vaccination of people aged over 80 years went live, some problems were observed with queues building at the front end of the process which limited social distancing. As part of the Lean Fundamentals MOOC beta test, a project was established to improve flow in the check-in process of the vaccination clinic for people aged over 80 years.

\section{MEASUREMENT}

The aim was to reduce the check-in time of over $80 \mathrm{~s}$ patients for COVID-19 vaccination. Following the Lean Fundamentals structured approach, a detailed current state analysis was undertaken comprising: mapping the current process (including the steps and inter-related flows of patients, staff, equipment and supplies); detailed timings of process elements; identification of process wastes and bottlenecks; and capturing staff and patient views. An overview of the process is shown in figure 1 below.

Lean emphasises process efficiency through the reduction of non-value adding processing time. Time-based operational metrics are used as a proxy for process efficiency. These include the cycle time for an individual process (or process step) and lead time across a sequence

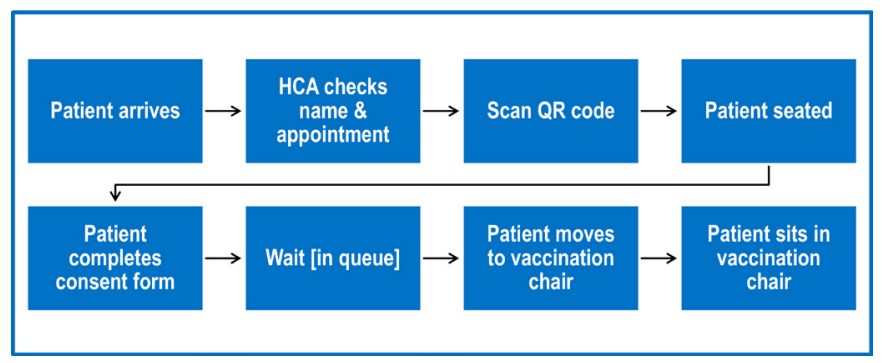

Figure 1 The process from arrival to sitting in vaccination clinic chair. HCA, healthcare assistant of processes. These metrics can be captured readily by observation and can be combined with process flow analysis to measure value-adding operational steps and safety checks as well as non-value adding waits and delays. Baseline measurement captured lead time data for a sample of patients from arrival to sitting in the clinic chair ready to receive their vaccination. Over the duration of a half-day observation session, lead time observations were collected for four patients.

\section{DESIGN}

As part of the Lean Fundamentals beta test, the Lean systematic improvement approach was used to undertake the project. This involved two beta testers following the MOOC's modules and structured approach. Both beta testers were improvement and change professionals, and both were redeployed from their substantive roles to support the local COVID-19 response. One worked in a local system coordination role and one worked within the hospital hub vaccination centre where the case took place. The Lean Fundamentals structured approach they followed was based on improvement kata. Kata is a Japanese term most closely associated with martial arts and refers to practice routines repeated regularly until actions become automatic habits. ${ }^{24}$ Improvement kata is rooted in the Lean improvement routines of Toyota Kata and has been linked to improvement capability building. ${ }^{24-26}$ Adapted for the healthcare context, improvement kata provided a structured, four-step routine for learning and applying improvement science. ${ }^{26}$ The first step in the improvement kata is to establish a clear improvement aim linked to an organisational priority. The second step is to study the current state in detail. The third step is to articulate target conditions, or future states, for how processes should operate to achieve the aim. The final step is to iterate towards achieving target conditions and the overall aim through successive application of plando-study-act (PDSA) experiments. ${ }^{24} 26$

Step one of improvement kata, to establish an improvement aim, was supported by module 1 of the Lean fundamentals MOOC, which helped participants establish and communicate their project using a standard, visual storyboard format.

Step two of improvement kata, current state analysis, was supported by modules 2-4 of the Lean Fundamentals MOOC which: introduced the principles of Lean to help participants consider value definition and how waste manifests within processes; demonstrated the effect of process variation and helped participants to design it out through observation, waste elimination and documentation of process standards; and introduced the seven flows of healthcare processes (patients, their families and carers, staff, medication, equipment, supplies and information) and how to observe, document and process map them.

Steps three and four of improvement kata, articulating target conditions and iterative experimentation, were 
supported by modules 5 and 6 of the MOOC, which introduced: a structured approach to continuous improvement through using the model for improvement and PDSA; and a five-step process to organise workplaces using visual methods to design more effective, efficient and reliable processes.

\section{STRATEGY}

The case example project strategy used the Lean Fundamentals MOOC structured approach and improvement kata. Once the aim was set, the current state analysis secured baseline measurements (described previously) but also sought to determine why queues were building by engaging with patients awaiting vaccination. Several themes emerged. First of all, it became apparent that the over 80 s target population preferred to arrive early for appointments. Second, this was exacerbated as some patients reported hearing about queues forming 'on the grapevine' and concluded, incorrectly, that arriving early would mean being vaccinated more quickly. Third, the winter weather, particularly when wet and windy, drove people to queue inside the limited reception wait space making social distancing difficult. Current state analysis also revealed that the physical environment of the clinic constrained line of sight between the vaccination room and the reception waiting area. This was contributing to delays in bringing patients forward to be ready for vaccination. Armed with this current state analysis, the project team shaped target conditions for improvement.

The first target condition was to ensure patients were fully informed about the need to adhere to appointment times. Additional communications were shared to reinforce this message.

The second target condition was to improve patient flow by ensuring patients were pulled towards the vaccination room in a timely manner. PDSA cycle 1 aimed to address this by using a healthcare assistant (HCA) as a 'spotter' between the reception wait area and vaccination room to request patients to come forward as soon as a vaccination chair was empty. While this appeared to make some improvement, the project team observed there was no easy way to identify the order in which patients had arrived.

The third target condition was to adhere to strict first-in first-out processing to ensure patients were seen equitably in order of arrival. PDSA cycle 2 introduced a numbering system using raffle tickets allocated to patients in order of arrival at check in. This, in addition to the HCA spotter, created sequential pull and appeared to further reduce the process lead time.

PDSA cycle 3 created a controlled location for prevaccination subwaiting. This comprised four to five chairs outside the vaccination room to facilitate pull of patients from the reception wait area to be ready for their vaccination. While this did not appear to impact in terms of lead time reduction, patient feedback was positive. Patients reported improved experience and a feeling of progressing more smoothly through the process. Introducing the controlled subwait also created more room in the reception wait area that facilitated social distancing.

A further change used the workplace organisation strategy to better manage items needed by the process (consent forms, appointment slips, vaccination cards, clipboards and pens). A table was used at the front end of the process to locate these items together and lay them out in the order required. While the impact of this change on lead time was not measured, the project team felt it was beneficial to the smooth operation of the reception area.

\section{RESULTS}

Postintervention measurement involved repeating lead time observations for further samples of four patients following each of the PDSA cycles (giving 16 patient lead time observations in total). Baseline and postintervention lead time measurement observations were compared using a run chart to assess the impact of PDSA tests of change (see figure 2). The changes introduced across PDSA cycles 1-3 achieved a reduction in lead time of $18 \%$ (though due to small sample sizes this may not be statistically significant).

\section{LESSONS AND LIMITATIONS}

As the national vaccine plan progresses, further cohorts from the JCVI's prioritisation will be invited to present for vaccination. ${ }^{23}$ Additional vaccines will become available, and recipients of first dose vaccination will return for their second dose. These factors will add complexity to the national programme and will present problems for local operational managers.

Although the problems faced will vary by local context and priority cohort focus, the knowledge and skills to solve those problems may be generic. The case example illustrates how a simple set of foundational improvement routines and operations management tools may be helpful. Furthermore, these routines and tools can be shared rapidly at scale via the Lean Fundamentals MOOC.

Improvement kata provided a simple, structured approach to developing and working towards an improvement challenge aim. The MOOC's modules provided tools and techniques to support detailed process analysis including consideration of the multiple flows of healthcare. As the complexity of managing vaccination operations increases with larger cohorts, multiple vaccines and second dose returners, the flows of healthcare might act as a useful framework for thinking about, mapping and optimising the multiple interacting elements that will need to come together to deliver effective and efficient processes.

The MOOC's module on continuous improvement provided guidance and structured templates for both documenting individual PDSA experiments and linking PDSA cycles sequentially as a record of experiments. Studies of PDSA application have reported a lack of fidelity with the method's intended approach. ${ }^{27} 28$ Documentation of all 


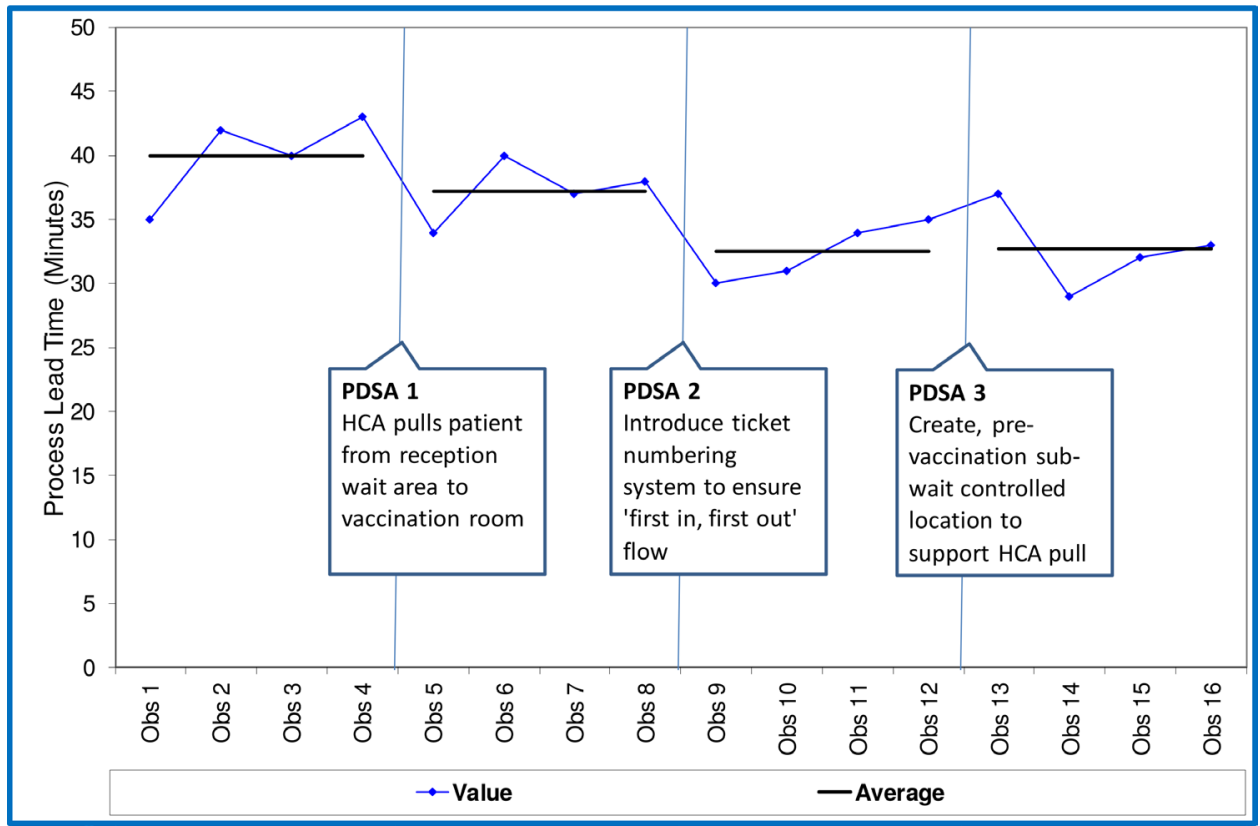

Figure 2 Patient observation lead time measurement time series and PDSA tests. HCA, healthcare assistant; PDSA, plan-dostudy-act.

PDSA stages, linking PDSA to learning, explicit predictions, iterative cycles, incremental testing and use of data over time are often lacking. ${ }^{27} 28$ The Lean Fundamentals MOOC covers explicitly the need for such fidelity to the PDSA approach and provides, through improvement kata, a structured way to practice. Improvement kata and the Lean Fundamentals MOOC may, therefore, be beneficial to enhance the fidelity of PDSA practice, and this may prove a useful area for future research.

Several limitations have been identified.

The study reports on a small-scale beta test and one case example of application by two beta testers. The case example project was undertaken rapidly over a short period of time. Therefore, there has been limited postintervention data collection. Furthermore, those involved in the beta test case example presented were experienced in improvement and change techniques, including Lean. This may limit the extent to which the experience of those beta-testing the Lean Fundamentals MOOC in the case example is generalisable to the wider NHS. Nevertheless, the case example demonstrated the potential applicability of Lean to improve vaccination processes.

Two of the authors, IMS and EB, worked on the design and delivery of the Lean Fundamentals MOOC and two authors, HS and AW, worked on the case example project. There is, therefore, the potential for positivity bias. To mitigate this, the authors have been reflexive and have adopted cautious, speculative language to not overstate the contribution of either the MOOC or the case example project. Furthermore, all PDSA tests have been reported including those that impacted minimally on the stated aim and those not measured for impact on lead time. However, unconscious positivity bias cannot be entirely ruled out.
Follow-up on application of the Lean Fundamentals content by other beta test sites has not been possible within the scope of this rapid report. However, given the urgency and scale of the national vaccination effort, the project and results to date have been shared as they may be of interest and value to colleagues working on similar challenges. Future studies might usefully evaluate the longer term impact of both Lean's contribution to vaccination processes and the Lean Fundamentals MOOC in building Lean improvement capability.

\section{CONCLUSION}

While this paper reports on just one case example of a small-scale improvement project, the massive online programme, of which it was a part, provides a mechanism for large-scale replication. Given the national imperative to achieve mass vaccination as rapidly as possible, systematic improvement methods and operations management approaches such as Lean may have a contribution to make. Massive online programmes, such as the Lean Fundamentals MOOC described here, may help with this effort by achieving timely knowledge transfer at scale.

Twitter Hollie Salisbury @HSalisbury1

Contributors IMS and EB were responsible for the planning, conduct, and reporting of the work described. IMS was responsible for writing the article and data analysis. EB contributed to the writing and revision of the article. HS and AW were responsible for case data collection and the revision of the article.

Funding The authors have not declared a specific grant for this research from any funding agency in the public, commercial or not-for-profit sectors.

Disclaimer The Health Research Authority online decision tool was used to determine that National Health Service (NHS) research ethics was not required for the study as it was considered to be evaluation of service improvement. 
Competing interests We have read and understood BMJ policy on declaration of interests and declare the following interests: IMS and EB work as improvement and transformation professionals in the NHS and led the design and delivery of the Lean Fundamentals MOOC and beta test. HS and AW work as improvement and transformation professionals in the NHS and worked on the case project.

Patient and public involvement Patients and/or the public were not involved in the design, or conduct, or reporting, or dissemination plans of this research.

Patient consent for publication Not required.

Provenance and peer review Not commissioned; externally peer reviewed.

Data availability statement All data relevant to the study are included in the article.

Open access This is an open access article distributed in accordance with the Creative Commons Attribution Non Commercial (CC BY-NC 4.0) license, which permits others to distribute, remix, adapt, build upon this work non-commercially, and license their derivative works on different terms, provided the original work is properly cited, appropriate credit is given, any changes made indicated, and the use is non-commercial. See: http://creativecommons.org/licenses/by-nc/4.0/.

ORCID iD

lain M Smith http://orcid.org/0000-0003-1138-2166

\section{REFERENCES}

1 World Health Organization. Covid-19 vaccines, 2021. Available: https://www.who.int/emergencies/diseases/novel-coronavirus-2019/ covid-19-vaccines

2 Department of Health \& Social Care. UK Covid-19 vaccines delivery plan. London: Department of Health \& Social Care, 2021: 46.

3 Joint Committee on Vaccination and Immunisation. Priority groups for coronavirus (COVID-19) vaccination: advice from the JCVI, 2020. Available: https://www.gov.uk/government/publications/prioritygroups-for-coronavirus-covid-19-vaccination-advice-from-the-jcvi30-december-2020 [Accessed 6 Jan 2021].

4 Dai T, Tayur S. Om Forum-Healthcare operations management: a snapshot of emerging research. M\&SOM 2020;22:869-87.

5 Smith I, Hicks C, McGovern T. Adapting lean methods to facilitate stakeholder engagement and co-design in healthcare. BMJ 2020;368:m35.

6 Sikka R, Morath JM, Leape L. The quadruple AIM: care, health, cost and meaning in work. BMJ Qual Saf 2015;24:608-10.

7 NHS England. Five year forward view. London: NHS England, 2014.

8 NHS England. The NHS long term plan. London: NHS England, 2019. www.longtermplan.nhs.uk

9 Ham C, Berwick D, Dixon J. Improving quality in the English NHS: a strategy for action. London: The King's Fund, 2016.

10 Boaden R, Harvey G, Moxham C. Quality improvement: theory and practice in healthcare. Coventry: NHS Institute of Innovation and Improvement, 2008
11 NHS Improvement. NHS partnership with Virginia Mason Institute, 2016. Available: https://improvement.nhs.uk/resources/virginiamason-institute/ [Accessed 21 Mar 2018].

12 Burgess N, Currie G, Crump B, et al. Improving together: collaboration needs to start with regulators. BMJ 2019;367:16392.

13 Blackmore CC, Kaplan GS. Lean and the perfect patient experience. BMJ Qual Saf 2017;26:85-6.

14 Burgess N. Evaluation of the NHS partnership with Virginia Mason Institute: four factors that foster continuous improvement capability in the NHS. Warwick Business School: Conventry, 2020.

15 Kirkwood A, Price L. Technology-enhanced learning and teaching in higher education: what is 'enhanced' and how do we know? A critical literature review. Learn Media Technol 2014;39:6-36.

16 Nicoll P, MacRury S, van Woerden HC, et al. Evaluation of Technology-Enhanced learning programs for health care professionals: systematic review. J Med Internet Res 2018;20:e131.

17 Health Education England. Technology enhanced learning. n.d. Available: https://www.hee.nhs.uk/our-work/technology-enhancedlearning

18 Smith IM, Bayliss E, Mukoro F. Capability building for large-scale transformational change: learning from an evaluation of a national programme. BMJ Open Qual 2021;10:e000980.

19 Guerrero M, Heaton S, Urbano D. Building universities' intrapreneurial capabilities in the digital era: The role and impacts of Massive Open Online Courses (MOOCs). Technovation 2021;99:102139.

20 Mahajan R, Gupta P, Singh T. Massive open online courses: concept and implications. Indian Pediatr 2019;56:489-95.

21 Khurshid Z, De Brún A, Moore G, et al. Virtual adaptation of traditional healthcare quality improvement training in response to COVID-19: a rapid narrative review. Hum Resour Health 2020;18:1-18.

22 Guest C, Wainwright P, Herbert M, et al. Driving quality improvement with a massive open online course (MOOC). BMJ Open Qual 2021;10:e000781.

23 Medicines and Healthcare products Regulatory Agency. Regulatory approval of Pfizer/BioNTech vaccine for COVID-19, 2020. Available: https://www.gov.uk/government/publications/regulatory-approval-ofpfizer-biontech-vaccine-for-covid-19 [Accessed 31 Dec 2020].

24 Rother M. The Toyota katA practice guide: practicing scientific thinking skills for superior results in 20 minutes a day. USA: McGraw Hill Professional, 2017.

25 Furnival J, Boaden R, Walshe K. A dynamic capabilities view of improvement capability. J Health Organ Manag 2019;33:821-34.

26 Proudlove N, Furnival J. Toyota katA: a missing link in quality improvement in healthcare? 27th European operations management association conference: EurOMA27. UK: Warwick, 2020: 1818-27.

27 Taylor MJ, McNicholas C, Nicolay C, et al. Systematic review of the application of the plan-do-study-act method to improve quality in healthcare. BMJ Qual Saf 2014;23:290-8.

28 McNicholas C, Lennox L, Woodcock T, et al. Evolving quality improvement support strategies to improve Plan-Do-Study-Act cycle fidelity: a retrospective mixed-methods study. BMJ Qual Saf 2019;28:bmjqs-2017-007605:356-65. 